\title{
The business education of Canadian plastic surgeons
}

\author{
Joy A Bliss RN BN MS PhD, Gregory G Caputy MD PhD \\ Aesthetica Plastic and Laser Surgery Center, Honolulu, Hawaii, USA
}

\begin{abstract}
JA Bliss, GG Caputy. The business education of Canadian plastic surgeons. Can J Plast Surg 1996;4(1):65-70. Business and economic aspects of a medical practice are rapidly becoming more complex. Physicians are at a crossroads in the manner by which medical and surgical care will be delivered in Canada, at the very base of which are the business aspects and management of health care. The purpose of this research study was to determine the business acumen of plastic surgeons in active practice. The resource base was Canadian plastic surgeons who are members of the Canadian Society of Plastic Surgeons. The intent of the questionnaire research study was to evaluate whether these surgeons perceive this area as necessary and whether they feel adequately prepared to manage this aspect of their practice. The findings of the research indicate that the plastic surgeons surveyed did perceive a need for business acumen in the practice of medicine. The majority felt they were not prepared adequately to deal with the business side of operating a medical practice and perceived a need for basic knowledge in the area of business. The implications of this research are that medical education has ignored this important aspect of preparing a physician to practise medicine in the present economic environment. Educational materials to structure and systematically disseminate business resource information need to be developed so that this group would be able to deal adequately with business-related problems when faced with them in medical practice. Due to the specialty-specific nature of the business needs, this education should likely occur during residency or fellowship training.
\end{abstract}

Key Words: Business, Canadian, Education, Plastic Surgeons, Practice

\section{La formation des plasticiens canadiens en administration}

RÉSUMÉ : Les aspects commerciaux et économiques de la pratique de la médecine sont de plus en plus complexes. Les médecins sont à un point tournant et doivent choisir de quelle façon les traitements médicaux et 
chirurgicaux seront dispensés au Canada, ce qui forme la base de la gestion des soins de santé. Le but de cette recherche était de mesurer l'habileté des plasticiens en pratique active à conduire leurs affaires. Le bassin de population étudiée était constitué de plasticiens canadiens membres de la Société canadienne des chirurgiens-plasticiens. Le but de l'étude menée au moyen d'un questionnaire était d'évaluer si les chirurgiens perçoivent cet aspect comme nécessaire et s'ils estiment être bien préparés à gérer cet angle de leur pratique. Les résultats de la recherche indiquent que les plasticiens interrogés ne percevaient pas la nécessité d'être de bons hommes d'affaires pour exercer la médecine. La majorité ont estimé ne pas être adéquatement préparés pour faire face à la $<<$ gestion $>>$ de leur pratique médicale et disaient avoir besoin de renseignements de base dans ce domaine. Les conclusions de la recherche sont que l'enseignement de la médecine néglige cet important aspect pour préparer les médecins à pratiquer leur profession dans le contexte économique actuel. Du matériel éducatif visant à structurer et à diffuser de façon systématique des renseignements sur la conduite des affaires, doit être mis à la disposition des médecins afin qu'ils arrivent à faire face adéquatement aux problèmes liés à l'administration des affaires dans leur pratique. À cause de la nature spécifique de cette spécialité, la formation devrait se faire au moment de la résidence ou de la formation postdoctorale.

The practice of medicine and surgery is becoming vastly more complex than ever before. While clinical information is ever increasing, the demands on a practice from a business standpoint are escalating even faster (1). Continued development of the medicalindustrial complex involving corporate, government and nonphysician interests have also altered the practice and setting of medicine today (2). To interact with, or even to understand, these recent developments, physicians and surgeons today need knowledge that encompasses medical expertise, management and business-related principles.

As medicine and surgery become ever more complex, better organization and greater expertise in financial, marketing and technical business skills become requirements for success. Often, obtaining these skills is not a desirable part of a physician's professional life (3), but it is a necessary part. Some physicians believe that they practise, not in medical or social isolation, but in business isolation (4). Attention to business and economic aspects of a medical practice has become so essential that it is now considered a matter of survival (5).

Various manuals, guidebooks, seminars and organizations that cover the practical knowledge of business start-up and ongoing management exist to fill the lacunae in the programs of many professional schools. Despite such programs and sources of assistance, problems exist for physicians in adjusting from academia to actual medical practice and in the specific business knowledge necessary for each specialty.

Business acumen varies within each medical and surgical specialty. No scientific study has been undertaken to determine physicians' and surgeons' perceived and real needs regarding management and business-related principles (6). The results obtained 
from the presented survey will assist in addressing these needs and provide information that can assist educators and management consultants to incorporate business and management concepts into the medical school curriculum and post MD continuing education.

The cosmetic portion of a plastic surgeon's practice is more openly businesslike than any other surgical or physician service. This is because the 'fee for service' aspect is more pronounced and because the service is purely elective. In addition, this is one of a small group of physicians and surgeons who may bill directly to the patient within the socialized Canadian health care system. This would suggest that these surgeons would have more of a need for business acumen. This detailed survey accurately studies the business acumen of this group of surgeons.

\section{MATERIALS AND METHODS}

\section{Population}

The target group of this study consisted of the entire population of 315 board certified plastic surgeons practising in Canada who are members of the Canadian Society of Plastic Surgeons. There is not an unmanageably large number of plastic surgeons across Canada, thus it was feasible to survey the entire population, thereby attaining a census survey. A list of registered plastic surgeons was obtained from the Canadian Society of Plastic Surgeons.

These practitioners are well-educated, experienced surgeons practising in the field of plastic surgery. Most of these surgeons have endured nine to 12 years of concentrated study and residency training before setting up their own practices. The practice setting varies among this group of surgeons. The various settings are as follows: group practice, solo-practice clinic, free-standing ambulatory, academic hospital setting, and clinical hospital setting.

\section{Survey design and instrument}

This study involved the use of descriptive exploratory research methodology (7). Data were obtained through a questionnaire-based survey. Subjects' opinions were obtained by means of a common (mailed) questionnaire. The questionnaire followed guidelines appropriate to proper instrumentation (8) with follow-up postcards, letters and re-mailings as appropriate. The items on the survey consisted of checklist-type questions and scaled items in which the respondents rated the frequency of certain events. Partial fill-in completion items were also used as options in the questionnaire.

The instrumentation technique was a mixed-mode method to gather all the necessary data (9). Ordinal data were scored on a five point scale. The questionnaire was divided into three basic categories. The first category determined whether there was a history of any undergraduate business education. The second category of questions determined whether an interest existed in acquiring additional business knowledge. The third category identified a commitment to learning more about the business aspects of medical practice.

A pretest or pilot study of this instrument was administered to a small group of individuals similar in background but more widely varied than the study population. The questionnaire is considered valid if it measures what is supposed to be measured. The 
content validity is assessed by having the pretesters examine the items to judge whether they are adequate for what they are supposed to measure. Criterion-related validity refers to whether the actual behaviour of subjects agreed with their expressed attitudes, opinions, or other answers. Criterion-related validity is attended to by protecting the respondent's anonymity. Greater truthfulness is usually obtained if anonymity is guaranteed (7).

The questionnaire is considered reliable if it measures the same situations or concepts consistently. The reliability can be measured by including repeated items throughout the questionnaire. In order to keep the questionnaire as concise as possible, this was not possible for the majority of questions but was used for key responses.

\section{RESULTS}

The first segment of the questionnaire dealt with demographics and practice type. Of the 315 plastic surgeons that were sent the survey questionnaire, $122(39 \%)$ responded. The largest group of respondents -- $30 \%$-- fell within the 'more than 20 years' range as a practising plastic surgeon, $25 \%$ were in the 11 to 15 years range, $20 \%$ had been practising from six to 10 years, $13 \%$ had been practising for 16 to 20 years, and $12 \%$ had practised only 0 to five years. These percentages correlated well with the total percentage of surgeons in each group.

A total of $24.5 \%$ of the respondents indicated that they operated a practice that was a combination of hospital integrated facility and solo practice; $10.5 \%$ indicated that they operated a practice solely within the hospital integrated facility. The remaining $65 \%$ operated practices within the various combinations of facilities and practices outlined in the definition of terms attached to each questionnaire. Nine percent of the remaining $65 \%$ indicated that they were entrepreneurs with various combinations of practice operations (ie, hospital integrated, office-based, free-standing and solo). The majority of these respondents had been operating a practice within the 11 to 15 year range. No statistical correlation was found between the type of practice and the business acumen of these surgeons.

The second segment of the questionnaire dealt with present comfort level in business and previous business background. Responses to the comfort level in reading business and economic material ranged from uncomfortable (18\%), to less than comfortable (24\%), to somewhat comfortable (22\%), to moderately comfortable $(26 \%)$, to very comfortable $(10 \%)$. The surgeons response to reading major business periodicals or newspapers such as the Wall Street Journal or Forbes magazine ranged from never $(36.5 \%)$, to rarely $(35.5 \%)$, to occasionally $(13 \%)$, to frequently $(10.5 \%)$, to often $(4.5 \%)$. Responses as to whether the surgeons could read and understand simple accounting statements ranged from no understanding $(12 \%)$, to with great difficulty $(21.5 \%)$, to with some difficulty $(32 \%)$, to with little difficulty $(23.5 \%)$, to very easily $(11 \%)$. The interest level in reading business and economic literature ranged from no interest (14\%), to rarely interested (22\%), to occasionally interested (30\%), to moderately interested (24\%), to very interested $(10 \%)$.

The surgeons' responses to having had any undergraduate or graduate business or economic courses ranged from $77 \%$ having taken no business courses, to $16 \%$ taking one course, to $6 \%$ taking two courses, to none taking three courses, to $1 \%$ taking four courses. 
Twenty-one percent of the surgeons had taken a simple accounting course whereas $79 \%$ had not. Eighteen percent had taken a finance course whereas $82 \%$ had not. Seven percent had taken a marketing course whereas $93 \%$ had not. Sixteen percent had indicated that they had prior business experience whereas $84 \%$ had none.

Figure 1 illustrates the perceived importance of business background in practices by Canadian plastic surgeons.

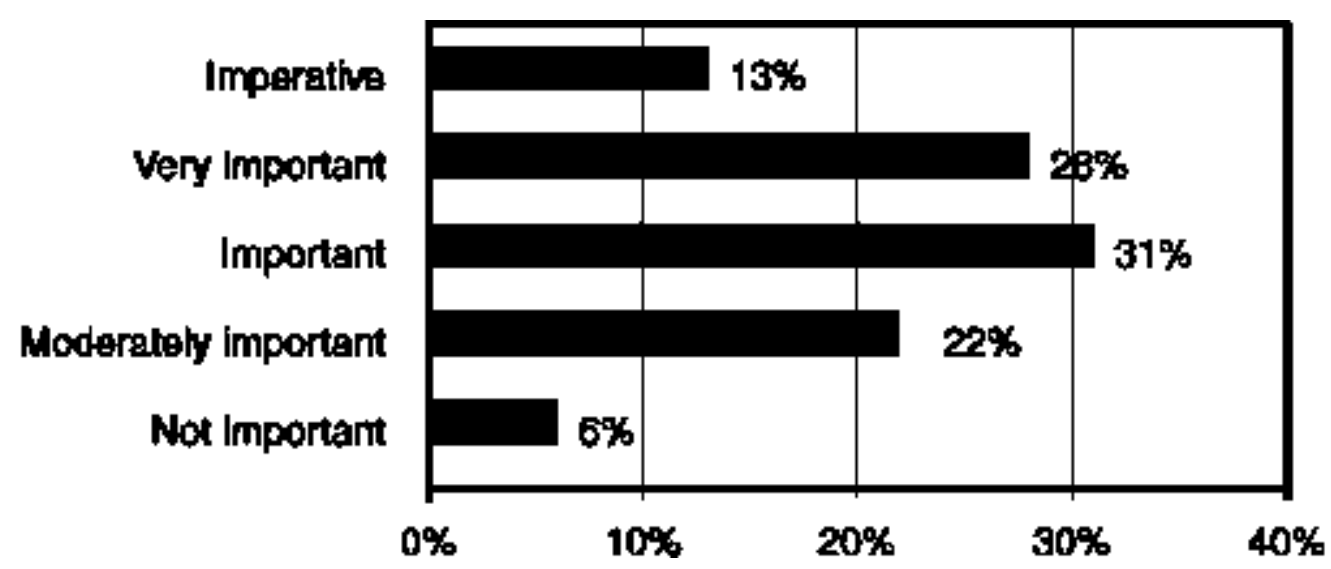

Figure 1) The importance of business background in medicine as perceived by Canadian plastic surgeons

The third segment of the questionnaire identified a commitment to learning more about the business of medicine and perceived need for learning about the business of medicine. The surgeons' responded to whether they felt that a general course in business to at least familiarize a physician with some of the business situations and perhaps the personnel finance area would be beneficial in the medical curriculum ranged from $93 \%$ indicating 'yes' to $6 \%$ indicating 'no' to $1 \%$ feeling unsure. The following are comments made by the respondents regarding this segment of the questionnaire.

Respondents with one to five years' practice experience:

- "An excellent concept and long overdue!"

- "Could possibly be offered as an option with medical ethics or other such courses."

- "There is precious little time in the curriculum of medicine as it is!"

Respondents with six to 10 years' practice experience:

- "Seriously lacking!"

- "Absolutely -- Physicians and dentists are the most common 'prey' for high risk financial investments."

- "Pertinent for hiring staff and staff motivation."

- "A must!"

- "So you can better understand what the people you hire do!"

Respondents with 10 to 15 years' practice experience:

- "In addition to the curriculum -- add hours!" 
- "Greatly needed -- fiscal responsibility requires business knowledge."

- " "Very definitely needed."

- "Long overdue!"

- "Could be an option not the final part of curriculum."

- "Not in Canada -- perhaps if one ran a private clinic!"

Respondents with 16 to 20 years' practice experience:

- "Essential!"

- "Should have full course but teach them too much and they'll stop medicine."

- Respondents with more than 20 years' practice experience:

- "Very brief and succinct. Better at the intern level! It's too soon in medical school."

- "I graduated from the University of Alberta in 1953 and have always felt that this was a great weakness in the medical curriculum."

- "It's no longer medicine -- it's a business!"

- "I was very unprepared when I started medicine!"

- "But when? Time does not allow."

The surgeons' responded as to whether they felt they could have benefited from some general business knowledge, in the form of business courses, which could have made the business of operating a medical practice a little less of an unknown venture, with responses ranging from $90 \%$ indicating 'yes', to $7 \%$ indicating 'no', to $3 \%$ not answering this question.

The surgeons' responses as to whether there could be a general business course designed especially for the physician's needs and where this course would be more beneficial and well received ranged from $5 \%$ indicating that a course should not be part of the medical curriculum, to $9 \%$ at the end of medical school/beginning of residency, to $50 \%$ wanting such a course in the last years of residency, to $25 \%$ when first going into practice, to $55 \%$ wanting continuing medical education courses beginning in medical school then continuing through residency and available in practice afterward, to $3 \%$ after being in practice one to two years, to $1 \%$ every five years, to $2 \%$ not responding to the question.

\section{DISCUSSION}

\section{Overview of health care systems}

Austin et al (10) note that when comparing the health care systems of the United States and Canada one must conclude that, at their core, each performs well in accordance with its founding principles. The US system is based largely on the principles of a (quasi) free market production of health services (although efforts of market modifications have added to the difficulties of controlling the system). The Canadian system is based principally on strong public policy control of health care expenditures. Each system has great successes, and shortcomings are largely inherent in their basic design tenets. The guiding principles underlying each system result in different allocations of responsibility and risks of those who control the systems and those who 
rely on them. Fiscal responsibility is becoming, more and more, a driving force within both systems. This demands basic business knowledge of those driving the system (often physicians).

Business acumen and experience barriers might be expected to be greatest during the start-up phase of any venture, when knowledge of a vast array of topics is vital to the launching and survival of a venture or business practice. Those who lack background in the language and methods of business may be doubly penalized by not knowing which questions to ask, and to whom to ask them. In the past, poorly equipped medical graduates may have made costly mistakes or struggled to operate efficient practices or clinics because they lacked essential information (11)

\section{Business education -- The current state}

The need for medically related business and managerial training for medical students and physicians is an area of education that has been frequently discussed among physicians in private and academic practice. Despite this, little has been done by physicians or by formal programs of medical or graduate medical education to address the need to introduce this type of training. Very little has been done in Canada regarding business education although there is a move toward this in the US. The most recent survey of medical students at Vanderbilt University (12) found that $50 \%$ of the students have an interest in learning more about the business of medicine. Medicine has a major business component. Recognizing the need for business skills, physicians are enrolling in MBA programs in increasing numbers. It is estimated that there are approximately 200 physicians who have a combined MBA-MD degree (13).

Some curriculum changes are underway. Lutz (5) points out that, in Minnesota, both the Mayo Clinic and the University of Minnesota, Duluth School of Medicine offer formal courses in medical economics, although neither is designed to do more than give a broad introduction to the complexities of the modern American health care system. Other studies suggest a need for business programs in medicine. In a survey of psychiatrists in Florida, $83 \%$ felt a lack of preparation for office management (14). In a survey of 73 physicians in Virginia, asking why they left primary practice, the results suggested overwork due to an unorganized office (14). Management more than any other business discipline needs to be taught to physicians (6). The University of California Los Angeles School of Medicine's Family Practice Center has also come to the same conclusions; business management skills are an essential part of medical practice (15).

A program at the Family Practice Center of Akron City Hospital has a practice management curriculum in which residents manage and supervise a model practice. The research into problem solving and the experience students develop make it practical (16).

In most medical schools in Canada, no formal business programs are integrated into the medical curriculum. The Family Practice Clinic at the University of Calgary Medical School allows residents to work in a clinic setting one day a week as if they were on their own, but it does not include the business aspects of running the clinic.

The literature reviewed indicated that a majority of the research and the literature on the business preparation and expertise, or lack of expertise, on the part of physicians is from the viewpoint of consultants to the medical practice. The practising surgeon has seldom been used as the resource pool to indicate these needs, even though usually he/she is the ultimate decision maker in the business aspects of the practice. Therefore, this 
research study was exploratory in design, the intent that the answer to some basic research questions would either provide the basis for further research, or indicate that the perceived need was not of significant magnitude to pursue further.

\section{Research findings}

The responses of 122 surgeons constituted a 39\% response rate. Dillman (17) refers to $30 \%$ return on questionnaires as being the acceptable norm. The $39 \%$ response rate by these surgeons is considered very good according to a marketing and research company that routinely surveys the Alberta Medical Association membership. Surveys they conducted as requested by the Alberta Medical Association usually brought in response rates of 20 to $25 \%$. The surgeon population used in this survey has a notorious reputation for not responding to questionnaires. Therefore, the response rate in this study is considered good to very good, considering the population being surveyed. This type of response could indicate that this topic is of great interest to the respondents.

The first segment of questions determined whether there was a history of any undergraduate business education. The plastic surgeons' responses relating to previous education indicated that only $23 \%$ had had at least one basic business, economic, finance, or marketing course. Only $21 \%$ had taken a simple accounting course, and only $18 \%$ had taken a finance course. Consequently, only about $66 \%$ could understand a simple accounting statement, which would include income statements, balance sheets and budget analyses.

The second segment, relating to the current level of interest in business and economic literature, suggested that 36\% (26\% from group 4 plus 10\% from group 5) had a relatively strong interest in increasing their background, but $42 \%$ (18\% from group 1 plus $24 \%$ from group 2) expressed a sense of being uncomfortable in reading business and economic material. As a result, $35.5 \%$ of the plastic surgeons rarely read the Wall Street Journal or other major business periodicals, and 36.5\% never read a business periodical. There was relatively strong emphasis on the importance of a management and business background in the practice of a plastic surgeon, as shown by a result of $41 \%$ ( $28 \%$ from group 4 plus $13 \%$ from group 5) of the respondents indicating the importance of this business background.

The third segment, indicating commitment to learning more about the business of medicine, revealed an overwhelming majority (93\%) of the plastic surgeons were in strong support of having a general business course to at least familiarize themselves with some of the business and personal finance areas of practice. There were a large number of additional comments (see the results section). This indicated a glaring perceived need by these surgeons for additional business education. Ninety percent indicated that they could have benefited from a business course that would have made the business side of operating a medical practice a little less of an unknown venture. This overwhelming response indicates that these surgeons do not feel that they have sufficient background in business to face and handle problems involved in the operation of the medical practice. This indicates a very strong commitment to learning more about the business of medicine and that a managerial/business background would be a valuable asset. As previously seen in category 1 , no formal business education was present in their training.

The surgeons were asked their opinion of the placement of special business courses in the medical curriculum to obtain maximum benefit. There was a wide range of 
responses, but the largest concentration of opinions was well defined. Fifty percent of the respondents indicated "during the last years of residency or right before the beginning of practice" as the most appropriate, and $25 \%$ indicated that a course would be more beneficial "when a physician first goes into practice". Although this group of surgeons may not be able to best judge when business training would be more useful to them, it seems reasonable that this time in their practice would be most beneficial and appropriate for some form of business education.

\section{Recommendations for future research}

This study indicates a need for more in-depth research to determine the scope of this problem. Information should be collected to determine the specific areas physicians perceived they need in the business aspects of operating a medical practice. Accessibility and practicality are necessary considerations in preparing business educational curricula. The teaching of medical acumen is conducted by medical specialists. The teaching of business acumen should be conducted by business specialists.

\section{CONCLUSIONS}

Canadian plastic surgeons have expressed the lack of business education and training as a problem area in the practice of surgery. If further research supports this implication, it stands to reason that an attempt should be made via basic medical education and continuing education to help bridge this gap. It must be emphasized that the intent of such education is not to make businessmen out of physicians and surgeons. The intent is simply to acquaint physicians with some of the problem areas and give them some general business knowledge so that they are able to deal adequately with these business-related problems when faced with them. Medicine is a profession in which patient care supersedes all other considerations. The business aspects of that care, however, are extremely important in being able to deliver optimal care. We are seeing this on the national level with health care reform. Health care costs are becoming massive in Canada and the United States, and it should be the responsibility of the educational programs to do everything possible to prepare physicians to operate their practices as efficiently and as cost-effectively as possible. The physicians would benefit, the patients would benefit and, as a result, society as a whole would benefit. The physicians would feel more comfortable with their total service and better care would result. An offshoot of this would be an improved image of the physician in the public's eye and an improved image of the entire health care and medical education systems.

ACKNOWLEDGEMENTS: This work comprises a portion of the work submitted in partial fulfilment of the requirements for the degree of $\mathrm{PhD}$ by JB to Walden University (Minneapolis, MN). This thesis was awarded the Blanche Wells Research Award by the Doctorate Association of New York Educators and Walden University for the year's best thesis. GC is a Canadian trained plastic surgeon in practice at Aesthetica Plastic and Laser Surgery Center in Honolulu, Hawaii. 


\section{REFERENCES}

1. Beck L, Anders GT, Sweeny D. Medical practice as a business. Pen Med J 1986;72:457.

2. Hillman AL, Nash DB, Kissick WL, Martin SP. Managing the medical-industrial complex. N Engl J Med 1986;315:511-3.

3. Munger CB. Providing better business for doctors. Mich Med J 1989;88:38-9.

4. Yawn B. Practicing the business in medicine. Minn Med 1987;70:11-2.

5. Lutz D. Medical education in the 80 's: Teaching the art, science, and business of medicine. Minn Med 1988;71:201-5.

6. Crimmel TS. An exploratory study of business acumen in solo/partnership medical practice. Master's thesis (MBA), Oral Roberts University, 1981:4-20.

7. Ary D, Jacobs C, Razavich A. Introduction to Research in Education, 3rd edn. New York:Holt, Rinehart and Winston, 1985:322-3.

8. Sudman S, Bradburn NM. Ask Questions. San Francisco: Jossey-Bass Publishers, 1982.

9. Emory WC. Business Research Methods. Homewood, Illinois: Richard D Irwin Inc, 1976:153-5.

10. Austin R, Hoye R, Kuber F. Health administrators in the US and Canada: Different allocations of responsibility and risk. Am Assoc Med Admin 1991;50:7-13.

11. Du Bois CG. The Business of Medical Practice. A Canadian Handbook. Toronto: Clark Pitmann Ltd, 1990:2-3.

12. Wholey MH, Chapman JE. Business and managerial education in the medical school curriculum. South Med J 1990;38:204-6.

13. Henry JB. A dual degree whose time has come. JAMA 1987;257:1727-8.

14. Lawson JG, McConnel JW. Teaching practice management in a family practice residency. J Med Ed 1976;51:858-64.

15. Werblum M, Martin LR, Drennan MR, Parker CE, Berggren RE. A complimentarybase curriculum in business practice management. J Fam Med 1977;4:893-906.

16. Aluise J. The physician as manager: What and how of practice management education. J Fam Pract 1977;2:2305-8.

17. Dillman DA. Mall and Telephone Surveys: The Total Design Method. New York:John Wiley \& Sons, 1978. 